\title{
Awareness of Tobacco Tax Policy and Public Opinion on Tobacco Tax Reform in Taiwan
}

\author{
Tsui-Fang $\operatorname{Lin}^{1)}$, Yun-Shan Chan ${ }^{1)}{ }^{*}$, Jennjou Chen ${ }^{2)}$
}

\begin{abstract}
This research investigates the general public's tobacco tax policy awareness and opinions on tobacco tax reform in Taiwan. To learn whether people are cognizant of tobacco tax policies and their preferences toward policy reform, we conducted a nationwide telephone survey in October 2016. Empirical methods used in this analysis include subgroup analysis and probit models. Our subgroup analysis shows that smokers, males, and individuals with more years of schooling are more likely to be knowledgeable about tobacco tax policies. As for public opinion on tobacco tax policy reform, non-smokers and more educated people prefer a tobacco tax hike policy. Females relative to males prefer to use regulatory programs to curb cigarette consumption. More educated people prefer an earmarked tax to a general excise tax. Males and more educated people tend to support a higher ratio of earmarked surcharge to overall tax revenue. The probit estimation results show that factors influencing people's tobacco policy awareness include smoking status, smokers in the household, gender, age, education, and marital status. The estimation results also demonstrate that, smoking status, gender, age, education, and marital status are important factors in determining people's preference for tobacco tax policy reform. To enhance the public's awareness of tobacco tax policies, the government could consider education campaigns, mass media, and social networking sites to provide information targeting certain groups of people such as non-smokers, females, and less educated individuals. To gain more public support of tobacco tax hike proposals, we also suggest that the government address the rationales behind taxing tobacco products and regularly examine whether the allocation of an earmarked surcharge is desirable and efficient. Lastly, in light of the fact that many people support non-price policies, we recommend that the government adopt diversified programs to curb tobacco consumption, in addition to increasing tobacco taxes.
\end{abstract}

[Keywords] tobacco tax policy awareness, tobacco tax reform, earmarked tax, public opinion

\section{Introduction}

Tobacco products in Taiwan have been under government control for a long period of time. The government tobacco monopoly system started in 1901 when Taiwan was ruled by Japan and continued for more than 100 years. Over the past century, the revenues derived from the monopoly system contributed greatly to government coffers. With the development of global free trade, Taiwan joined the World Trade Organization in 2002 and ended the monopoly system. The government subsequently liberalized domestic tobacco and alcohol markets and enacted two laws: Tobacco and Alcohol Administration Act and Tobacco and Alcohol Tax Act. According to the Tobacco and Alcohol Tax Act, a general tobacco excise tax and tobacco health and welfare surcharge are imposed on tobacco products, and both of them are unit taxes. Tobacco excise taxes are part of general consolidated tax revenues and

1) Department of Public Finance, National Taipei University, Taiwan

2) Department of Economics, National Chengchi University, Taiwan

* Corresponding author. E-mail : yunshan@gm.ntpu.edu.tw 
controlled under the Ministry of Finance in Taiwan. In contrast, the surcharges of tobacco products are earmarked for a special purpose legislated in advance. Without changing the laws, the authorities are not able to use the surcharges for other purposes. ${ }^{8}$ The majority of government revenue generated from the tobacco health and welfare surcharge is controlled by the Ministry of Health and Welfare.

In the beginning of 2002 , the excise taxes on tobacco products were set at NT $\$ 590$ per 1,000 cigarettes, NT $\$ 590$ per kilogram for cut tobacco, NT $\$ 590$ per kilogram for cigars, and NT $\$ 590$ per kilogram for other tobacco products. The surcharges of tobacco products were set at NT $\$ 250$ per 1,000 cigarettes, NT $\$ 250$ per kilogram for cut tobacco, NT $\$ 250$ per kilogram for cigars, and NT $\$ 250$ per kilogram for other tobacco products. From 2002 to 2009, the Taiwan government amended the Tobacco and Alcohol Tax Act twice, raising the surcharges of tobacco products from NT $\$ 250$ to NT $\$ 500$ and then to NT $\$ 1,000$ per 1,000 cigarettes or per kilogram. Tobacco excise taxes, however, remained the same until the third amendment in 2016. The increased tobacco excise tax revenues, from NT $\$ 590$ to NT $\$ 1,590$ per 1,000 cigarettes or per kilogram, however, are earmarked for the long-term care program in Taiwan.*

The precise allocation of the tobacco health and welfare surcharge has been amended several times since its introduction. During the study period, $50 \%$ of surcharges go to general National Health Insurance (NHI) reserves; $24.2 \%$ of surcharges are used to support medical care for rare disease patients, cancer prevention, tobacco prevention, and general healthcare; and $11.8 \%$ help develop preventive medicine and improve healthcare quality. Economically disadvantaged citizens obtain the fourth largest share, followed by spending on a variety of medical services, many of which may have no direct relationship to tobacco consumption. Finally, $8 \%$ of surcharges are used to finance social welfare and long-term care programs, while $1 \%$ of surcharges are used to curb tobacco tax evasion.

Tax policy is the product of political decision making, ${ }^{7}$ and economic and social factors as well as the existing political environment inevitably influence its formation and design. Currently, the smoking prevalence rate for males is close to $30 \%$ in Taiwan while that for females is less than 5\%. From a public choice perspective, many parties, including voters, political representatives, bureaucrats, experts, and interest groups, play a role in tax policy making and tax policy reform. The main purpose of this paper is to investigate the general public's awareness of tobacco tax policies and their opinions on tobacco tax reform in Taiwan. Our study contributes to the existing literature by constructing a rich and detailed nationwide telephone survey and exploring people's awareness of tobacco tax policies and their preferences for tobacco tax policy reform from many angles. A better understanding of these factors is vital for the design of tobacco taxes.

\section{Literature Review}

This paper examines people's tobacco tax policy awareness and explores their preferences for tobacco tax policy reform in Taiwan. We study whether people are aware of a variety of policy elements, such as the meanings of a general excise tax and an earmarked tax (tobacco health and welfare surcharge), the distribution of the tax and surcharge, and government tax hike proposals. In addition, we investigate people's opinion on a range of reform options, including tax hike proposals, regulation and price policies, general use and earmarked purposes, and the ratio of earmarked use over total tax burden. Below, we review the literature covering both general and earmarked taxes and tobacco policy preference.

\section{General versus Earmarked Taxes}

There are different opinions on earmarking, ${ }^{1,2,6,8-10,12,18}$ with the main advantages of earmarked taxes described as follows. First, they are similar to user fees, which reflect the benefit principle of taxation and are more likely to gain public support. Second, since earmarked tax revenues are designated by law for special purposes, voters may

\footnotetext{
* http://law.moj.gov.tw/Eng/LawClass/LawContent.aspx?PCODE=G0330010
} 
therefore feel that they are better informed of public spending. Third, the use of earmarked taxes may avoid convulsive movement within the bureaucracy and ensure stable funding for certain programs. Finally, greater stability and continuity of funding may also reduce costs associated with implementing public expenditure projects through speedy completion.

The main problems of earmarked taxes, however, encompass the following points. First, the application of a user-fee principle that increases welfare by earmarked taxes may not work under asymmetric information. Second, earmarking taxes could introduce inflexibility in government policy. Since earmarked taxes are designated to fund certain programs, they are not able to finance other projects even if those specific programs are outdated or overfunded. Additionally, a high proportion of taxes that are earmarked could lead to erosion in budgetary efficiency. Third, unlike general budgets, most designated expenditure programs are not subject to comprehensive budget reviews. The lack of official scrutiny may lead to a loss of transparency over public expenditure programs. Furthermore, earmarking taxes may encourage rent-seeking behavior by interest groups. Fourth and lastly, earmarked taxes that are designated for unrelated expenditures may produce adverse distributional effects.

\section{Public Opinions on Tobacco Policies and Use of Tobacco Taxes}

Researchers from different countries have investigated people's opinions on tobacco policies and the use of tobacco taxes. Torabi et al. interviewed 800 people from the state of Indiana in the United States. ${ }^{14}$ They found that $91 \%$ of participants believed that smoking may cause cancer, $89 \%$ of respondents supported legislations that would fund educational programs to help prevent young people from smoking, and $82 \%$ of people said that the government could cut other spending to finance educational programs. Moreover, nearly $86 \%$ of respondents supported a tax increase on cigarettes for educational programs on tobacco-related diseases, and $75 \%$ of people supported an increase in tobacco taxes that would be used on tobacco-related research.

Torabi conducted repeated interviews in 1989, 1990, and 1992 to examine the trend and stability of public opinions on tobacco tax use and raising tobacco taxes in Indiana. ${ }^{13}$ While the prevalence of former smokers remained the same and the average consumption of cigarettes by current smokers increased by year, respondents were more aware of the dangers of secondhand smoke. The authors found an overall stronger support on restricting smoking areas in public places and using tobacco taxes to fund educational programs and research on tobaccorelated diseases.

Hamilton et al. analyzed the referendum voting outcomes of 351 towns in Massachusetts. ${ }^{3}$ Their findings showed that self-interest may affect the attitude toward tobacco policies, and that the use of tax revenues may also play certain roles. Smokers usually prefer to avoid taxation, while non-smokers tend to favor it. However, once the tax revenues are earmarked for tobacco control and similar uses, the authors noted that tobacco taxation obtains stronger support.

Hanewinkel and Isensee interviewed 27,608 people aged 14 to 98 between 2001 and 2005 to examine individuals' opinions on tobacco tax increases in Germany. ${ }^{4}$ During this period, the authorities raised tobacco taxes 5 times. They found that tobacco price increases do in fact lead to a substantial change in the smoking behavior of individuals. People either reduce their consumption or switch to cheaper tobacco products. Using the same dataset, Hanewinkel and Isensee further analyzed factors affecting an individual's support on tobacco tax policies. ${ }^{5}$ They suggested that supporters are more likely to be female, aged 41 or above, well-educated, and living alone. Compared to unemployed people, employed or retired respondents tend to support tobacco policies. They also stated that population support grew along with consecutive tax increases, but the high support rate mainly came from non-smokers.

Tsai et al. investigated public attitudes toward cigarette taxation prior to the Taiwan authorities imposing a NT $\$ 5$ per pack tax earmarked for tobacco control programs in $2002 .{ }^{15}$ The authors stated that smoking status and economic factors mainly determine the responses of people toward the tax increase, which is consistent with previous studies showing that non-smokers usually support tobacco taxation. Among smokers, heavy smokers tend to have a lower support rate for earmarked taxation. Nearly $60 \%$ of respondents suggested the earmarked 
tax revenues be used for health promotion and related education; only $10-20 \%$ of people suggested the tax revenues be used for related research and smuggling control.

Wilson et al. surveyed 1,376 adult smokers and studied the characteristics of smokers and their support for dedicated tobacco taxes in New Zealand. ${ }^{16}$ The authors found that smokers tend to support a tax hike if the revenue is to be used to finance smoking cessation and health promotion programs. Pacheco traced public opinions on tobacco use and tobacco control legislation in the United States over time. ${ }^{11}$ The author noted that an overall increase in the awareness of public health and support of anti-smoking legislation at the federal, state, and local levels coincided with the decline of smoking prevalence.

Yeh et al. interviewed 1,007 smokers in Taiwan to analyze the effect of a hypothetical increase in the health and welfare surcharge of tobacco products on smokers' behavior. ${ }^{18}$ They found that hypothetical cigarette price increases would motivate $30 \%$ of smokers to adopt smoking-related changes and increase the cessation rate at the population level. Highly addicted smokers, however, would more likely switch their tobacco consumption to cheaper brands.

A growing body of studies has explored the public awareness of tobacco-related diseases and public support on different tobacco policies, but few have discussed public opinions on the allocation of tobacco tax revenues. Since tax policy is the product of political decision making and tax measures are found to be effective at reducing tobacco consumption, ${ }^{7,18}$ it is of particular interest to examine whether the allocation of tobacco tax revenues may affect public support for tobacco taxation. This paper thus investigates the general public's awareness of tobacco tax policies and their opinion on tobacco tax reform in Taiwan, including their preference for the allocation of tobacco tax revenues.

\section{Statistical Analysis}

\section{Data and Variables}

To explore people's awareness of tobacco tax policies and preferences for tobacco tax policy reform, we constructed a detailed nationwide survey and interviewed 1,503 adults over 18 years old by phone in October 2016, before the third amendment of the Tobacco and Alcohol Tax Act. After deleting observations with missing information, the effective sample size is 1,179. The computer-assisted telephone interview (CATI) was administrated by The Election Studies Research Center at National Taipei University under the supervision of our research team. Survey questions include individuals' socio-economic information, smoking participation, cigarette consumption, perception regarding cigarette consumption and second-hand smoke, awareness of tobacco tax policy, and attitude towards future policy reform. Socio-economic variables consist of gender, age, education, marital status, employment status and monthly wage income. Data on smoking participation and cigarette consumption are collected to examine whether or not smokers and non-smokers exhibit differences in awareness of tobacco tax policies and preferences for reform options.

Table 1 lists the definitions of the major dependent variables used in our analysis. Table A.1 lists the awareness and preference questions in our original questionnaire. Six dummy variables (A1-A6) are constructed to investigate people's understanding of the current tobacco tax policy. In the original questionnaire, we asked respondents whether they can tell the differences between a general excise tax and a surcharge; whether they are aware that consumers need to pay a health and welfare surcharge when buying cigarettes; whether they are aware that consumers need to pay an extra tobacco tax in addition to a health and welfare surcharge, a value added tax, and a tariff; whether they are aware that the amount of the health and welfare surcharge is higher than that of the general tobacco excise tax during the sample period; whether they know the amount of the total tax burden, including the general tobacco excise tax and surcharge imposed on a pack of cigarettes; and whether they know that the government plans to impose another NT $\$ 25$ general tobacco excise tax and surcharge on a pack of cigarettes. 
Table 1. Definitions of Major Variables

A1: whether respondents can tell the differences between general excise tax and health and welfare surcharge imposed on cigarettes $(\mathrm{A} 1=1$ if yes, $\mathrm{A} 1=0$ if otherwise)

A2: aware that consumers need to pay health and welfare surcharge when buying cigarettes (A2=1 if yes, $A 2=0$ if otherwise)

A3: aware that consumers need to pay general tobacco excise tax in addition to health and welfare surcharge, value added tax and tariff when buying cigarettes (A3=1 if yes, $A 3=0$ if otherwise)

A4: among the total tax burden of a pack of cigarettes, aware that the amount of health and welfare surcharge is higher than that of the general excise tax ( $A 4=1$ if yes, $\mathrm{A} 4=0$ if otherwise)

A5: aware of the total amount of the tax burden including the general excise tax and health and welfare surcharge (A5=1 if can answer the approximate amount, A5=0 if otherwise)

A6: aware that the government plans to have a tax hike policy which imposes another NT $\$ 25$ general excise tax and surcharge on a pack of cigarettes ( $\mathrm{A} 6=1$ if yes, $\mathrm{A} 6=0$ if otherwise)

P1: opinions regarding the total amount of tax burden $(\mathrm{NT} \$ 31.8)$ on a pack of cigarettes including general tobacco excise tax and health and welfare surcharge $(\mathrm{P} 1=1$ if too low, $\mathrm{P} 1=0$ if otherwise)

P2: opinions regarding effectiveness of regulatory policy (warning labeling and restrictions on smoking areas) and tax policy to curb smoking ( $\mathrm{P} 2=1$ if regard regulatory program as more effective, $\mathrm{P} 2=0$ if otherwise)

P3: opinions on taxes or surcharges imposed on cigarettes be used for specific purposes such as NHI programs and health related expenditures $(\mathrm{P} 3=1$ if prefer earmarked use, $\mathrm{P} 3=0$ if otherwise)

P4: opinions on ratio of earmarked surcharges to total tax burden, current ratio of surcharge over total tax burden for tobacco products is $60 \%$. ( $\mathrm{P} 4=1$ if too low, $\mathrm{P} 4=0$ if otherwise)

Taking the first awareness variable (A1) as an example, before respondents answered the corresponding question, trained interviewers explained to them that government revenue consists of many parts such as taxes and surcharges. Respondents then were asked whether they can tell the differences between these two frequently mentioned terms. In our sample, over one third of respondents recognize that taxes and surcharges are different in terms of purpose and function. We create a dummy variable named A1, using the above information. A1 is coded as 1 if the respondent knows that these two terms have different meanings. A1 is coded as 0 if the respondent cannot tell or is not sure about the differences between taxes and surcharges. Right after the respondents answered question A1, our trained interviewers provided them with the information that excise taxes are used for general purpose while surcharges are earmarked for some specific uses before respondents answered the next five awareness questions.

After respondents answered all awareness related questions, they were informed of the range of retail prices and various taxes imposed on a pack of cigarettes. As a consequence, respondents have perfect information about taxes and surcharges associated with cigarette consumption and can express their opinions on various tobacco tax reform policies. In our questionnaire, four questions relate to people's preferences for tobacco tax policy reform. This enables us to construct tax policy preference variables (P1-P4). First, respondents were asked about their opinions regarding whether the current total tax burden, including general excise tax and surcharge, is appropriate, too high, or too low. Second, respondents were asked about their opinions regarding the effectiveness of regulatory policy and tax policy to curb smoking. Respondents were told that regulatory measures include restricting smoking areas or adding warning labels on tobacco products. Third, respondents were asked whether or not they prefer excise taxes on tobacco products to be earmarked on specific programs, just like the current design of the health and welfare surcharge. Fourth, respondents were asked about their opinions on the ratio of earmarked surcharge to overall cigarette tax burden. 
In the case of the first preference variable, we code P1 as 1 if respondents regard the current tax burden on cigarettes as too low. We find that over $25 \%$ of respondents think that the current tax burden on consuming cigarettes is not high enough. For those who reported that current tax burden is too low, we further asked them how much more tax should be imposed on cigarettes. More than $50 \%$ of the respondents who answered "too low" think that the government could consider imposing another NT $\$ 50$ tax on cigarettes. Therefore, we argue that the binary variable P1 represent an individual's preference for a tobacco tax hike.

\section{Subgroup Analysis}

We next want to investigate whether respondents' knowledge of tobacco tax policy and their opinion on tobacco tax policy reform may significantly be different among various subgroups. We divide the full sample by smoking status, gender, and education level. The t test results in Table 2 show that statistically significant differences do exist among subgroups.

The subgroup analysis by smoking status demonstrates that smokers relative to non-smokers are more knowledgeable about current tobacco tax policy. For example, 53\% of smokers know that the meanings of a tax and a surcharge are different, while only $40 \%$ non-smokers do; $82 \%$ of smokers are aware that consumers need to pay a tobacco health and welfare surcharge when purchasing cigarettes, while $73 \%$ of non-smokers know that; $46 \%$ of smokers know that consumers need to pay a general tobacco excise tax in addition to a tobacco health and welfare surcharge, a value added tax, and a tariff, while only $32 \%$ of non-smokers are aware of the general tobacco excise tax. $46 \%$ of smokers recognize that, within the total tax burden of a pack of cigarettes, the amount of the health and welfare surcharge is greater than that of the general tobacco tax. However, only $21 \%$ of non-smokers recognize that the amount of the health and welfare surcharge is greater than that of the general tobacco tax. With regard to the exact amount of tax burden, including general tobacco tax and surcharge, $27 \%$ of smokers know the exact amount of the tax burden of a pack of cigarettes, but only $16 \%$ of non-smokers recognize that. In particular, $83 \%$ of smokers are aware that the government plans to impose a NT $\$ 25$ general tobacco tax or surcharge on a pack of cigarettes, while only $52 \%$ of non-smokers are aware of the news during the sample period.

As for people's public opinion on tobacco tax policy reform, $32 \%$ of non-smokers believe that the current tax burden on cigarettes is too low, while only $9 \%$ of smokers share the same opinion. In terms of policy alternatives, $40 \%$ of non-smokers agree that regulatory measures rather than price policy are more effective, while $35 \%$ of smokers think so. Concerning the allocation of a tax and surcharge, over $60 \%$ of smokers and non-smokers prefer

Table 2. Subgroup Analysis

\begin{tabular}{|c|c|c|c|c|c|c|c|c|c|}
\hline \multirow[b]{2}{*}{ Variables } & \multicolumn{3}{|c|}{ Smoking Status } & \multicolumn{3}{|c|}{ Gender } & \multicolumn{3}{|c|}{ Education } \\
\hline & $\begin{array}{c}\text { Non-Smokers } \\
(1,021)\end{array}$ & $\begin{array}{c}\text { Smokers } \\
(158)\end{array}$ & $\begin{array}{c}\text { Significantly } \\
\text { Different }\end{array}$ & $\begin{array}{c}\text { Female } \\
(682)\end{array}$ & $\begin{array}{l}\text { Male } \\
(497)\end{array}$ & $\begin{array}{l}\text { Significantly } \\
\text { Different }\end{array}$ & $\begin{array}{l}\text { High School } \\
\text { and below } \\
(527)\end{array}$ & $\begin{array}{c}\text { Associate } \\
\text { Degree } \\
\text { and above } \\
(652)\end{array}$ & $\begin{array}{l}\text { Significantly } \\
\text { Different }\end{array}$ \\
\hline $\mathrm{A} 1$ & $40 \%$ & $53 \%$ & $* * *$ & $37 \%$ & $47 \%$ & $* * *$ & $38 \%$ & $45 \%$ & $* * *$ \\
\hline $\mathrm{A} 2$ & $73 \%$ & $82 \%$ & $* * *$ & $72 \%$ & $77 \%$ & $* *$ & $69 \%$ & $79 \%$ & $* * *$ \\
\hline A3 & $32 \%$ & $46 \%$ & $* * *$ & $30 \%$ & $39 \%$ & $* * *$ & $31 \%$ & $37 \%$ & $* *$ \\
\hline A4 & $21 \%$ & $46 \%$ & $* * *$ & $20 \%$ & $31 \%$ & $* * *$ & $20 \%$ & $27 \%$ & $* * *$ \\
\hline A5 & $16 \%$ & $27 \%$ & $* * *$ & $14 \%$ & $22 \%$ & $* * *$ & $14 \%$ & $20 \%$ & $* * *$ \\
\hline A6 & $52 \%$ & $83 \%$ & $* * *$ & $49 \%$ & $67 \%$ & $* * *$ & $57 \%$ & $56 \%$ & \\
\hline $\mathrm{P} 1$ & $32 \%$ & $9 \%$ & $* * *$ & $30 \%$ & $28 \%$ & & $23 \%$ & $33 \%$ & $* * *$ \\
\hline $\mathrm{P} 2$ & $40 \%$ & $35 \%$ & & $41 \%$ & $36 \%$ & $*$ & $39 \%$ & $39 \%$ & \\
\hline P3 & $67 \%$ & $61 \%$ & $*$ & $66 \%$ & $67 \%$ & & $60 \%$ & $72 \%$ & $* * *$ \\
\hline $\mathrm{P} 4$ & $24 \%$ & $26 \%$ & & $20 \%$ & $31 \%$ & $* * *$ & $17 \%$ & $30 \%$ & $* * *$ \\
\hline
\end{tabular}

Note: "***" is significant at $0.01, " * * *$ is at 0.05 , and "*" is at 0.1 Type I error levels. 
the excise tax imposed on cigarettes to be used for specific purpose. As mentioned earlier, the ratio of the surcharge over the total tax burden was $60 \%$ during the sample period, and $24 \%$ of non-smokers and $26 \%$ of smokers agree that this ratio is too low.

Our subgroup analysis by smoking status shows that smokers are much more knowledgeable about current tobacco policy, such as the existence of the general tobacco excise tax and tobacco health and welfare surcharge, the distribution of tax and surcharge, and the amount of tax burden. As for public opinion on tobacco tax policy reform, around $32 \%$ of non-smokers believe that the current tax burden is too low, whereas a much lower proportion of smokers share the same opinion. This result may be due to the self-interest motive.

We next conduct subgroup analysis by gender. Compared to their female counterparts, males generally have more knowledge of current tobacco tax policy. As to the preference for policy reform, compared to their male counterparts, more females agree that regulatory policies are more effective than price policies at reducing the smoking prevalence rate. With regard to the ratio of surcharge to overall tax burden, a significantly higher proportion of males believe that this ratio is too low.

The subgroup analysis by education level shows that more educated individuals relative to less educated individuals have a greater knowledge of current tobacco policy. As for public opinion on tobacco tax policy reform, over $33 \%$ of highly educated people believe that the current tax burden is too low, while less than $25 \%$ of less educated people share the same opinion. In addition, $72 \%$ of individuals with more years of schooling prefer the tobacco excise tax and surcharge to be used for specific purposes, while $60 \%$ of people with only a high school education or less think so. Finally, 30\% of highly educated respondents think that the ratio of surcharge over the total tax burden is too low, while $17 \%$ of less educated respondents believe so.

It is of note that there are large variances between preference variables. For instance, earmarking preference (P3) is far more supported than other tax policy preferences such as tax hike preference. In Taiwan, the tobacco health and welfare surcharge imposed on cigarettes is currently earmarked for NHI reserves and health related expenditures such as specific medical treatment programs, welfare and long-term care programs. Before respondents answered P3, they were informed by interviewers on the current use of welfare surcharges of tobacco products. In Taiwan, the NHI program has the highest public satisfaction rate (around 80\%) among all government programs. It is therefore not surprising to observe that individuals prefer taxes or surcharges spent on specific purposes since they expect those revenues will be used to finance NHI related expenditures. Furthermore, one plausible reason for a relatively lower support for increasing the ratio of surcharge to overall tax burden (P4) could be that this question seems more abstract to respondents. Some respondents may find difficulty understanding the allocation of tobacco tax revenues during the phone interview. Table A.1 presents the original questions used to construct P1-P4.

\section{Empirical Results}

To investigate individuals' awareness of tobacco tax policies and their preferences for tobacco tax policy reform, we choose to use probit models since the dependent variables are binary variables in our analysis. The correlations among six awareness variables are relatively low ranging from 0.12 to 0.29 . We also check the correlations among all explanatory variables and rule out the collinearity problem. Table 3 reports the estimation results of the awareness of tobacco tax policy, and Table 4 reports the estimation results of public opinion on tobacco tax policy reform.

Dependent variables in Table 3 include six questions regarding people's understanding of current tax policy. For instance, the first binary variable is whether or not people recognize the differences between a general excise tax and a surcharge. This binary variable is coded as 1 if the respondents know the difference between the two and coded as 0 if they do not know the difference. As mentioned in the introduction section, the general tobacco excise tax is collected for general budget use, but not earmarked on specific programs. In contrast, the tobacco health and welfare surcharges are used for specific purposes, such as financing national health insurance reserves, specific medical programs, and long-term care services. 
Table 3. Estimation Results of Tobacco Tax Policy Awareness

\begin{tabular}{|c|c|c|c|c|c|c|}
\hline Variables & A1 & $\mathrm{A} 2$ & A3 & A4 & A5 & A6 \\
\hline \multirow{2}{*}{$\begin{array}{l}\text { Agree that smoking will damage } \\
\text { people's health }\end{array}$} & 0.0223 & 0.0867 & -0.486 & -0.101 & -0.432 & 0.278 \\
\hline & $(0.403)$ & $(0.394)$ & $(0.406)$ & $(0.395)$ & $(0.465)$ & $(0.446)$ \\
\hline \multirow{2}{*}{$\begin{array}{l}\text { Agree that second-hand smoke will } \\
\text { damage people's health }\end{array}$} & 0.0548 & 0.0822 & -0.187 & 0.170 & 0.128 & -0.392 \\
\hline & $(0.336)$ & $(0.315)$ & $(0.336)$ & $(0.340)$ & $(0.430)$ & $(0.396)$ \\
\hline \multirow{2}{*}{ Smoker } & $0.372^{* * * *}$ & $0.292^{* *}$ & $0.273^{* *}$ & $0.658 * * *$ & $0.270 * *$ & $0.739 * * *$ \\
\hline & $(0.122)$ & $(0.148)$ & $(0.122)$ & $(0.127)$ & $(0.132)$ & $(0.135)$ \\
\hline \multirow{2}{*}{$\begin{array}{l}\text { There is at least one other family } \\
\text { member who smokes }\end{array}$} & 0.0530 & $0.209^{* *}$ & 0.0791 & 0.133 & $0.336^{* * * *}$ & $0.355^{* * *}$ \\
\hline & $(0.0901)$ & $(0.0982)$ & $(0.0912)$ & $(0.0992)$ & $(0.104)$ & $(0.0919)$ \\
\hline \multirow{2}{*}{ Male } & 0.119 & 0.0259 & $0.186^{* *}$ & $0.195^{* *}$ & $0.288 * * *$ & $0.364 * * *$ \\
\hline & $(0.0865)$ & $(0.0949)$ & $(0.0874)$ & $(0.0950)$ & $(0.101)$ & $(0.0870)$ \\
\hline \multirow{2}{*}{ Age } & $0.0123^{* * *}$ & 0.000854 & 0.00249 & $-0.00817^{* *}$ & 0.00462 & 0.00113 \\
\hline & $(0.00335)$ & $(0.00365)$ & $(0.00341)$ & $(0.00369)$ & $(0.00396)$ & $(0.00334)$ \\
\hline \multicolumn{7}{|l|}{ Education } \\
\hline $\begin{array}{l}\text { Elementary school and below } \\
\text { (reference group) }\end{array}$ & . & . & . & . & $\cdot$ & . \\
\hline \multirow{2}{*}{ Junior high school } & $0.346^{*}$ & $0.908 * * *$ & 0.209 & $0.445^{*}$ & $0.569 * *$ & 0.0599 \\
\hline & $(0.194)$ & $(0.195)$ & $(0.202)$ & $(0.250)$ & $(0.275)$ & $(0.189)$ \\
\hline \multirow{2}{*}{ Senior high school } & $0.631^{* * *}$ & $0.976^{* * *}$ & $0.467 * * *$ & $0.644^{* * *}$ & $0.768 * * *$ & $0.448 * * *$ \\
\hline & $(0.164)$ & $(0.163)$ & $(0.168)$ & $(0.209)$ & $(0.242)$ & $(0.161)$ \\
\hline \multirow{2}{*}{ Associate degree } & $0.831 * * *$ & $1.091^{* * *}$ & $0.729 * * *$ & $0.785^{* * * *}$ & $1.257^{* * * *}$ & $0.496^{* * *}$ \\
\hline & $(0.184)$ & $(0.187)$ & $(0.187)$ & $(0.224)$ & $(0.254)$ & $(0.180)$ \\
\hline \multirow{2}{*}{ College degree } & $0.775^{* * * *}$ & $1.097 * * *$ & $0.593 * * *$ & $0.748^{* * * *}$ & $0.782^{* * *}$ & $0.365^{* *}$ \\
\hline & $(0.173)$ & $(0.178)$ & $(0.178)$ & $(0.217)$ & $(0.251)$ & $(0.169)$ \\
\hline \multirow{2}{*}{ Graduate degree } & $1.030 * * *$ & $1.088^{* * * *}$ & 0.280 & $0.713^{* * * *}$ & $0.894 * * *$ & $0.432^{* *}$ \\
\hline & $(0.218)$ & $(0.229)$ & $(0.225)$ & $(0.259)$ & $(0.295)$ & $(0.217)$ \\
\hline \multirow{2}{*}{ Married } & 0.0404 & $0.286^{* * *}$ & 0.170 & 0.138 & -0.00354 & $0.264^{* *}$ \\
\hline & $(0.103)$ & $(0.108)$ & $(0.105)$ & $(0.113)$ & $(0.127)$ & $(0.103)$ \\
\hline \multirow{2}{*}{ Full-time job } & -0.142 & 0.205 & -0.0509 & -0.0374 & $0.284 *$ & -0.107 \\
\hline & $(0.130)$ & $(0.142)$ & $(0.136)$ & $(0.140)$ & $(0.157)$ & $(0.141)$ \\
\hline \multirow{2}{*}{ Constant } & $-1.587^{* * *}$ & -0.781 & -0.662 & $-2.058^{* * *}$ & $-1.917^{* * *}$ & -0.669 \\
\hline & $(0.491)$ & $(0.519)$ & $(0.488)$ & $(0.542)$ & $(0.543)$ & $(0.532)$ \\
\hline Wage dummies & Yes & Yes & Yes & Yes & Yes & Yes \\
\hline County dummies & Yes & Yes & Yes & Yes & Yes & Yes \\
\hline Sample size & 1,179 & 1,179 & 1,179 & 1,179 & 1,179 & 1,179 \\
\hline
\end{tabular}

Note: Marginal effects are reported. $" * * * "$ is significant at $0.01, " * * "$ is at 0.05 , and $" * "$ is at 0.1 Type I error levels. 
After controlling for other variables, Table 3 presents that smoking status and education level significantly impact people's awareness of tobacco tax policy in all cases. Smokers relative to non-smokers are more likely to be knowledgeable about current tobacco tax policy. Married individuals and those living with smoking family members tend to know some current tobacco tax policies better. People with more years of education are also more aware of a variety of tobacco tax policy. Moreover, the probability of policy awareness increases with education level. For some policy awareness variables, males relative to females understand tobacco tax policy better. Smokers understand tobacco tax policy better could be due to their self-interest motive. One plausible explanation for a positive correlation between education and policy awareness is that people with more years of schooling have more access to public policy information or they process information more effectively, and thus they know better about tobacco policies. Relative to females, males knowing tobacco tax policy better could be due to the fact that most smokers in Taiwan are males. These findings are in line with those found in previous studies.

Dependent variables in Table 4 consist of four policy preferences. For instance, the first column shows the estimation results of the policy preference toward increasing the tax burden. In this case, a binary variable is coded as 1 if individuals respond that the current tobacco tax burden is too low. A range of socio-economic variables are also taken into account in the probit model. The estimation results of preferences for tobacco policy reform are shown in Table 4. As expected, smokers are less likely to prefer a tax hike policy, which is consistent with our findings in the subgroup analysis. From the viewpoint of public choice, self-interested individuals are more likely to support policy proposals that benefit themselves the most. We also find that males prefer a higher ratio of surcharge to overall cigarette tax revenue. Married respondents tend to support a tax hike policy and prefer an increase in the ratio of earmarked surcharge to overall tax burden. Moreover, the age variable is positively associated with the earmarking preference. Among all explanatory variables, education significantly influences people's tax policy preferences. For instance, people with more years of education support a tax hike on tobacco products and the earmarked use of the tobacco tax and surcharge. They also prefer using regulatory programs to curb cigarette consumption and raising the ratio of surcharge.

\section{Conclusion and Discussion}

Similar to many countries around the world, Taiwan imposes a general excise tax and surcharge on tobacco products. A tax on tobacco products may reduce tobacco consumption and enhance people's health. In addition, taxing inelastic tobacco products could be a good way to raise government revenue. This research paper's main objective is thus to investigate the general public's awareness of tobacco tax policy and opinion on tobacco tax reform in Taiwan. In a democratic society, understanding people's awareness of tobacco tax policy and their preferences for reform options can provide policymakers with useful insights when formulating tobacco tax policy.

Compared to their counterparts, smokers, males, and individuals with more years of schooling are more likely to be knowledgeable about tobacco tax policies. Most respondents know that cigarette prices contain a surcharge earmarked for specific programs, but fewer respondents recognize that the cigarette prices also contain an excise tax for general use. Moreover, most people are not sure about the exact tax amount applied to cigarettes and cannot tell the differences between a general excise tax and a surcharge. Around $29 \%$ of respondents support a tax hike on tobacco products, and $96 \%$ of them are non-smokers. In terms of the use of the excise tax revenue, $66 \%$ of respondents support an earmarked tax. Based on subgroup analysis, smokers and non-smokers exhibit significant differences in tobacco policy awareness and preferences for policy reforms. The results that nonsmokers are more likely to support a tobacco tax hike and earmarked taxes gain more public support are consistent with findings in this line of research.

The probit estimation results show that factors influencing people's tobacco policy awareness include smoking status, smokers in the household, gender, age, education, and marital status. The estimation results also demonstrate that, after controlling for other covariates, smoking status, gender, age, education, and marital status are important factors in determining their preference for tobacco tax policy reform. As for enhancing people's awareness of tobacco tax policies, the government can consider using a variety of ways including education 
Table 4: Estimation Results of Preferences for Tobacco Policy Reform

\begin{tabular}{|c|c|c|c|c|}
\hline Variable & $\mathrm{P} 1$ & $\mathrm{P} 2$ & P3 & $\mathrm{P} 4$ \\
\hline \multirow{2}{*}{$\begin{array}{l}\text { Agree that smoking will damage } \\
\text { people's health }\end{array}$} & -0.692 & 0.542 & -0.319 & -0.177 \\
\hline & $(0.559)$ & $(0.467)$ & $(0.406)$ & $(0.446)$ \\
\hline \multirow{2}{*}{$\begin{array}{l}\text { Agree that second-hand smoke will } \\
\text { damage people's health }\end{array}$} & 0.998 & 0.287 & 0.540 & 0.343 \\
\hline & $(0.672)$ & $(0.372)$ & $(0.353)$ & $(0.397)$ \\
\hline \multirow{2}{*}{ Smoker } & $-0.920 * * *$ & -0.0272 & -0.0821 & 0.00676 \\
\hline & $(0.158)$ & $(0.123)$ & $(0.125)$ & $(0.131)$ \\
\hline \multirow{2}{*}{$\begin{array}{l}\text { There is at least one other family } \\
\text { member who smokes }\end{array}$} & -0.0626 & -0.00418 & 0.119 & 0.0494 \\
\hline & $(0.0969)$ & $(0.0890)$ & $(0.0924)$ & $(0.0991)$ \\
\hline \multirow{2}{*}{ Male } & 0.0770 & -0.0549 & -0.000476 & $0.357 * * *$ \\
\hline & $(0.0911)$ & $(0.0863)$ & $(0.0897)$ & $(0.0925)$ \\
\hline \multirow{2}{*}{ Age } & -0.00420 & -0.00258 & $0.00768 * *$ & 0.00114 \\
\hline & $(0.00349)$ & $(0.00329)$ & $(0.00347)$ & $(0.00357)$ \\
\hline \multicolumn{5}{|l|}{ Education } \\
\hline $\begin{array}{l}\text { Elementary school and below } \\
\text { (reference group) }\end{array}$ & $\cdot$ & · & . & · \\
\hline \multirow{2}{*}{ Junior high school } & 0.177 & $0.487^{* *}$ & $0.311^{*}$ & 0.398 \\
\hline & $(0.225)$ & $(0.194)$ & $(0.184)$ & $(0.243)$ \\
\hline \multirow{2}{*}{ Senior high school } & $0.381^{* *}$ & $0.484 * * *$ & $0.542^{* * * *}$ & $0.550 * * *$ \\
\hline & $(0.181)$ & $(0.164)$ & $(0.154)$ & $(0.204)$ \\
\hline \multirow{2}{*}{ Associate degree } & 0.285 & $0.609 * * *$ & $0.744^{* * *}$ & $0.830 * * *$ \\
\hline & $(0.200)$ & $(0.180)$ & $(0.177)$ & $(0.221)$ \\
\hline \multirow{2}{*}{ College degree } & $0.613 * * *$ & $0.358^{* *}$ & $0.719 * * *$ & $0.898 * * *$ \\
\hline & $(0.187)$ & $(0.173)$ & $(0.165)$ & $(0.213)$ \\
\hline \multirow{2}{*}{ Graduate degree } & $0.635^{* * * *}$ & 0.302 & $1.124 * * *$ & $1.025^{* * *}$ \\
\hline & $(0.232)$ & $(0.217)$ & $(0.228)$ & $(0.251)$ \\
\hline \multirow{2}{*}{ Married } & $0.352^{* * * *}$ & 0.0290 & 0.0333 & $0.308^{* * *}$ \\
\hline & $(0.110)$ & $(0.102)$ & $(0.104)$ & $(0.114)$ \\
\hline \multirow{2}{*}{ Full-time job } & -0.176 & 0.0747 & 0.0694 & 0.00749 \\
\hline & $(0.141)$ & $(0.133)$ & $(0.134)$ & $(0.142)$ \\
\hline \multirow{2}{*}{ Constant } & $-1.348^{*}$ & $-1.350 * *$ & -0.537 & $-1.800^{* * *}$ \\
\hline & $(0.707)$ & $(0.525)$ & $(0.506)$ & $(0.547)$ \\
\hline Wage dummies & Yes & Yes & Yes & Yes \\
\hline County dummies & Yes & Yes & Yes & Yes \\
\hline Sample size & 1,179 & 1,179 & 1,179 & 1,179 \\
\hline
\end{tabular}

Note: Marginal effects are reported. "***" is significant at $0.01, " * * "$ is at 0.05 , and "*" is at 0.1 Type I error levels. 


\section{Appendix}

Table A.1 Awareness and Preference Questions in the Original Questionnaire

\begin{tabular}{|c|c|c|}
\hline \multirow{2}{*}{ A1 } & Question: & Are you aware of the differences between "tax" (稅) and "surcharge" (捐) among government revenue? \\
\hline & Response: & (1) yes; (2) no; (3) not sure; (4) refuse to answer \\
\hline \multirow{2}{*}{ A2 } & Question: & Do you know that tobacco health and welfare surcharge are included in the retail price of cigarettes? \\
\hline & Response: & (1) yes; (2) no; (3) not sure; (4) refuse to answer \\
\hline \multirow{2}{*}{ A3 } & Question: & $\begin{array}{l}\text { In addition to the tobacco health and welfare surcharge, business tax, and tariff (for imported cigarettes), do } \\
\text { you know that you still need to pay a tobacco excise tax when purchasing cigarettes? }\end{array}$ \\
\hline & Response: & (1) yes; (2) no; (3) not sure; (4) refuse to answer \\
\hline \multirow{2}{*}{ A4 } & Question: & $\begin{array}{l}\text { When consumers buy one pack of cigarettes, they need to pay both excise taxes and surcharges. In your } \\
\text { opinion, which one costs consumers more? The tobacco health and welfare surcharge or the excise tax? }\end{array}$ \\
\hline & Response: & (1) surcharge; (2) excise tax; (3) do not know; (4) not sure; (5) refuse to answer \\
\hline \multirow[t]{2}{*}{ A5 } & Question: & $\begin{array}{l}\text { Do you know the amount of the total tax burden imposed on one pack of cigarettes including the tobacco } \\
\text { health and welfare surcharge and tobacco excise tax? }\end{array}$ \\
\hline & Response: & (1) ___ (dollar amount); (2) do not know; (3) not sure; (4) refuse to answer \\
\hline \multirow{2}{*}{ A6 } & Question: & $\begin{array}{l}\text { Do you know that the government plans to impose another NT } \$ 25 \text { tax (including tobacco health and welfare } \\
\text { surcharge and tobacco excise tax) on each pack of cigarettes? }\end{array}$ \\
\hline & Response: & (1) yes; (2) no; (3) not sure; (4) refuse to answer \\
\hline \multirow{2}{*}{ P1 } & Question: & $\begin{array}{l}\text { In your opinion, is the current total tax burden, NT } \$ 31.8 \text { (consisting of tobacco health and welfare surcharge } \\
\text { and tobacco excise tax), imposed on a pack of cigarettes too high, too low or appropriate? }\end{array}$ \\
\hline & Response: & (1) too high; (2) too low; (3) appropriate; (4) not sure; (5) refuse to answer \\
\hline \multirow{2}{*}{ P2 } & Question: & $\begin{array}{l}\text { In your opinion, which of the following programs would be more effective in curbing the smoking prevalence } \\
\text { rate? Tobacco tax hike or enact more regulatory programs such as restricting smoking areas or requiring } \\
\text { warning labels? }\end{array}$ \\
\hline & Response: & $\begin{array}{l}\text { (1) tobacco tax hike; (2) regulatory programs; (3) both programs would produce the same effect; (4) uncertain; } \\
\text { (5) depends; (6) no idea; (7) refuse to answer }\end{array}$ \\
\hline \multirow{2}{*}{ P3 } & Question: & $\begin{array}{l}\text { In your opinion, should excise taxes or surcharges imposed on tobacco products be used for specific purposes } \\
\text { such as NHI programs and health related expenditures? }\end{array}$ \\
\hline & Response: & $\begin{array}{l}\text { (1) should be used on specific programs; (2) general use; (2) both; (3) uncertain; (4) depends; (5) no idea; (6) } \\
\text { refuse to answer }\end{array}$ \\
\hline \multirow[t]{2}{*}{$\mathrm{P} 4$} & Question: & $\begin{array}{l}\text { Among the total government revenue raised currently from taxes and surcharges for tobacco consumption, } \\
40 \% \text { are raised by excise taxes that will be used for general purposes while } 60 \% \text { are raised by earmarked } \\
\text { surcharges that will be used for specific purposes. In your opinion, is } 60 \% \text { of the revenues raised by surcharges } \\
\text { too high, too low, or appropriate? }\end{array}$ \\
\hline & Response: & (1) too high; (2) too low; (3) appropriate; (4) not sure; (5) refuse to answer \\
\hline
\end{tabular}


campaigns, mass media and social networking sites to provide information especially for certain groups of people such as non-smokers, females and less educated individuals.

Possibly due to the self-interest motive, non-smokers rather than smokers prefer a tax hike on tobacco products. A tobacco tax hike could curb cigarette consumption and raise tax revenue. Nevertheless, to what extent a tobacco tax hike will reduce cigarette consumption and increase government revenue hinges on the demand elasticity of cigarettes, tax change and tax evasion. It is worth noting that a tax hike on tobacco products may produce regressive results and hurt smokers. To gain more public support for tobacco tax hike proposals, we suggest that the government address the rationales behind taxing tobacco products and regularly examine whether the allocation of an earmarked surcharge is desirable and efficient. Lastly, in light of the fact that many people support non-price policies, we recommend that the government adopt diversified programs to curb tobacco consumption, in addition to increasing tobacco taxes.

\section{Acknowledgements}

This work was supported by Taiwan's Ministry of Finance (105mof004) and Ministry of Science and Technology (MOST107-2914-I-004-001-A1). This paper was presented at the 2018 Allied Social Science Associations (ASSA) Annual Meeting in Philadelphia. We thank conference participants for their thoughtful comments and suggestions. Interpretations and conclusions contained herein do not represent those of Ministry of Finance and Ministry of Science and Technology in Taiwan. All errors are our own.

\section{References}

[1] Bös, D. Earmarked taxation: welfare versus political support. Journal of Public Economics 2000; 75(3): 439462.

[2] Buchanan, J. M. The economics of earmarked taxes. Journal of political economy 1963; 71(5): 457-469.

[3] Hamilton, W. L., Biener L., Rodger, C. N. Who supports tobacco excise taxes?: Factors associated with towns' and individuals' support in Massachusetts. Journal of public Health Management and Practice 2005; 11(4): 333-340.

[4] Hanewinkel, R., \& Isensee, B. Five in a row-reactions of smokers to tobacco tax increases: population-based cross-sectional studies in Germany 2001-2006. Tobacco Control 2007; 16: 34-37

[5] Hanewinkel, R. \& Isensee, B. Opinion on tobacco tax increase: Factors associated with individuals' support in Germany. Health Policy 2008; 86: 234-238

[6] Hsiung, B. A note on earmarked taxes. Public finance review 2001; 29(3): 223-232.

[7] Holcombe, R.G. Tax policy from a public choice perspective. National Tax Journal 1998; 51(2): 359-371.

[8] International Tax \& Investment Center. Special Report: Are earmarked taxes on alcohol and tobacco a good idea? Evidence from Asia 2013.

[9] McCleary, W. A., \& Mundial, B. Earmarking government revenues: does it work? Country Economics Department, World Bank 1989.

[10] McMahon, W. W., \& Sprenkle, C. M. Earmarking and the theory of public expenditure. National Tax Journal (pre-1986) 1972; 25(2): 229.

[11] Pacheco, J., Trends-Public opinion on smoking and anti-smoking policies. Public. Opinion Quarterly 2011; 75(3): 576-592.

[12] Petit, P., \& Nagy, M. J. How to design and enforce tobacco excises? International Monetary Fund 2016.

[13] Torabi, M. R. Trends of public opinion on tobacco use and public policy. Indiana Medicine 1996; 89: 132-135.

[14] Torabi, M. R., McAllister, L., \& Kotecki, J. E. Public opinion on tobacco use, its taxes and public policy. Indiana medicine: the journal of the Indiana State Medical Association 1994; 87(2): 134-138.

[15] Tsai,Y. W., Yen. L. L., Yang, C.L., \& Chen, P. F. Public opinion regarding earmarked cigarette tax in Taiwan. BMC Public Health 2003; 3(1): 42. 
[16] Wilson, N., Weerasekera, D., Edwards, R., Thomson, G., Devlin, M., \& Gifford, H. Characteristics of smoker support for increasing a dedicated tobacco tax: national survey data from New Zealand. Nicotine \&Tobacco Research 2010; 12 (2):168-173.

[17] World Health Organization. Earmarked tobacco taxes: lessons learnt from nine countries. World Health Organization 2016.

[18] Yeh, C. Y., Schafferer, C., Lee, J. M., \& Hsieh, C. J. Smoking-related changes or brand switching? Smokers' anticipated responses to a large increase in Taiwan's Tobacco Health and Welfare Surcharge. Public health 2016; 136: 41-47. 